\title{
Evaluation of Sensitivity and Resistance of Bacteria Associated With Dental Abscesses in Lebanese Population
}

Asmar Ghada $^{1 *}$, Cochelard Dominique ${ }^{2}$, Mokhbat Jacques $^{3}$, Lemdani Mohamed ${ }^{4}$, Haddadi Ahmed $^{5}$ and Ayoub Fouad ${ }^{6}$

${ }^{1}$ Doctorate School for Science and Technology, Research Platform for Environmental Sciences, Faculty of Dental Medicine; Lebanese University, Beirut, Lebanon

${ }^{2}$ Professor, Biomathematics Laboratory EA 2694 - Lille 2 University, France

${ }^{3}$ Professor, Division of Infectious Diseases, School of Medicine, Lebanese American University, Beirut, Lebanon

${ }^{4}$ Professor, Biomathematics Laboratory EA 2694 - Lille 2 University, France

${ }^{5}$ Public health: Epidemiology and Quality of Care, Lille 2 University, France

${ }^{6}$ Professor and Dean, Faculty of Dental Medicine, Department of Basic Sciences, Faculty of Dental Medicine, Lebanese University, Beirut, Lebanon

Received: December 08, 2017; Accepted: February 01, 2018; Published: February 12, 2018

*Corresponding author: Ghada Asmar, Doctorate School for Science and Technology, Research Platform for Environmental Sciences, Faculty of Dental Medicine; Lebanese University, Beirut, Lebanon, E-mail: ghadaasmar@gmail.com; Tel: +9613234189

\begin{abstract}
Objectives: Inappropriate prescription of antibiotics for the treatment of dental abscesses is not uncommon. Knowledge about the root canal flora is crucial in order to determine the most effective antibiotics and to limit the emergence of resistant bacteria. The objective of the study was to isolate the root canal flora from teeth associated with dental abscesses, and determine the sensitivity and resistance of the incriminated bacteria to different antibiotics.
\end{abstract}

Methods: Bacterial samples obtained from patients presenting with dental abscesses to Lebanese dental clinics were analyzed to determine the types of involved bacteria. Bacterial sensitivity and resistance were tested.

Results: 42 and 85 samples were obtained from chronic and acute dental abscesses, respectively. 19 / 85 samples were from patients with dental abscesses and aggravating clinical signs. The majority of the detected bacteria were facultative anaerobes. Obligate anaerobes were found in teeth with acute dental abscesses and aggravating clinical signs. Gram-positive bacteria showed the highest antibiotic resistance. Penicillin had the highest sensitivity levels.

Conclusion: The role of the dentists in making a correct diagnosis is emphasized considering the presence of virulent bacteria. Penicillin should be the primary antibiotic of choice when required in the context of the treatment of dental abscesses.

Keywords: Antibiotics; Bacteria; Acute Abscess; Cellulitis; Dental Infection;

\section{Introduction}

The microbiome of the orofacial sphere is rich, varied and of commensal nature. However, any perturbation (dental, periodontal infection, etc.) of the oral flora balance can render these germs pathogenic and virulent. These germs can be aerobe, anaerobe or facultative. Any prescribed antibiotherapy should take into consideration the nature of these germs and their sensitivity in order to be efficient [1], and to reduce the development risk of resisting germs and super infections along with risks of allergies.

Since 1990, the importance of antibiotic resistance of oral flora bacteria has increased [2]. The empirical usage of antibiotics in dentistry is a major factor in its development; it represents 8 to $10 \%$ of prescribed antibiotics [2]. The molecular choice of antibiotics prescribed is limited. These prescriptions should target the germs causing the infection. These germs are diversified and their prevalence varies from one study to another. This diversification is due to several factors (i.e. identification method, geographical location, etc...) [3]. Moreover, these prescriptions are based on the results of epidemiological and clinical studies previously conducted over a variety of population samples. Hence, they are based and assumed over a probabilistic reasoning [4]. Therefore, it was interesting to i) determine the ecology of the microbial endodontic flora of the Lebanese population in the case of acute and chronic abscesses, ii) recognize in both abscess types the most probable resisting germs to the most prescribed antibiotics in dentistry; and iii) determine if the germs associated with acute abscesses with and without aggravating clinical signs differ in their sensitivity to the antibiotherapies.

\section{Methodology and Analyses}

\section{Ethical Approval}

This study concerned prospective and non-interventional 
data patients. All patients were informed about the aim of the study and written consent was obtained from each participant. This study was approved by the Institutional Review Board and Ethical Committee of the Lebanese University.

\section{Study Design}

This Prospective multicentric study was conducted over 9 months at the dental clinic of the Lebanese University along with 24 dental clinics located in Beirut and its outskirts. Eligible patients met the following criteria: men or women aged 16 and above, clinically diagnosed with acute or chronic dental abscesses. Patients who needed hospitalization were not included in the study. Moreover, patients were excluded for the following reasons: missing patient's data file or antibiogram.

\section{Sampling}

Bacterial samples were taken by aspiration of the pus with a needle and a syringe if a fluctuant swelling was present, or by intra-canal sampling.

Pus aspiration was done after disinfecting the skin around the mouth with Betadine, followed by the disinfection of the oral cavity with Chlorhexidine Gluconate at $0.12 \%$ : $15 \mathrm{ml}$ for 30 seconds [5]. Pus was aspirated with a syringe through an intact mucosa. The content of the syringe was then injected into the tube containing the transport medium.

Intra-canal samples were taken from the largest canal after proper isolation of the tooth with a rubber dam. Intra-canal samples were taken pursuant to the protocol described in the following studies:

\section{Disinfection of the concerned area:}

The extra oral area was disinfected with Betadine. A rubber dam was placed "Opal Dam" (Ultradent Products) was used to ensure proper isolation. The tooth was cleaned with pumice. The rubber dam and the tooth were then disinfected with $3 \%$-hydrogen peroxide and $2.5 \%$-NaOCL solutions. The access cavity was prepared; the rubber dam and the tooth were disinfected again with $2.5 \%-\mathrm{NaOCl}$ which was then deactivated with a sterile sodium thiosulphate solution at $5 \%$ [6].

\section{Intra Canal Sampling:}

The bacterial sample was taken by introducing a sterile endodontic K-file of size 10 or 15 in the dental canal up to the tooth apex with a light rotational movement. The samples were placed individually in tubes containing (regenerated thioglycollate agar) which were transferred immediately to the laboratory [6].

\section{Microbiological Method}

The microbiological analysis of the total sampling specimens was performed as per the standard culture method ("Galerie Pasteur" and « biochemical system »by API System) and antibiograms using the disc diffusion technique 'Kirby-Bauer".

Germs were grouped into facultative aero-anaerobe germs (microaerophilic)/obligate anaerobes; then in positive/negative Grams along with cocci and bacilli (annex: microbiological method)

\section{Statistical Analysis}

The following information was recorded: sex, age, clinical diagnosis (acute or chronic abscess as by the "American Association of Endodontist"), type of antibiotics prescribed and results of the microbiological analysis (microbial identification and sensitivity) [8].

A descriptive statistical analysis of the population considered by the current study and that of the identified germs and their sensitivity was performed by way of computing percentages and averages.

A Chi-Square Goodness of Fit test for categorical variables (facultative and obligate anaerobe germs) was performed. The proportion of the resisting germs during a prescription in the treating groups with 3 types of antibiotics (penicillin, erythromycin and clindamycin).

The data was analyzed statistically using SPSS, version 19 with the significance level of $5 \%$.

\section{Results}

Out of 741 patients that attended the Lebanese University clinic and the 24 dental clinics; 563 who met the inclusion criteria were selected. 436 were excluded due to absence of dental abscess or antibiogram and 178 patients were not included because less than 16 years old. 138 samples were collected and sent to the laboratory; 10 cases were not included (10 antibiograms were for 10 patients not included because younger than 16 years old) and one case was excluded (because it was canceled by the laboratory due to a wrong manipulation of the sampling). So, $127 / 436$ (29.12\%) from 138/436 (31.65\%) were taken into consideration (Flowchart 1).

From the 127 included patients, 42 suffered from chronic abscesses and 85 from an acute abscess out of which 19 presented aggravating clinical signs.

The Male/Female ratio is of 1.3 (56.7\% men and $43.3 \%$ women). The average age was $43.53+/-14.88$ years. The median and the interquartile range were 45 years and 26 years, respectively.

The pus culture obtained from the 127 specimens identified 144 germs and 5 Candidas albicans (fungus) out of 88 specimens, a normal flora for 6 specimens. Twenty-three and 10 samples obtained from teeth associated with acute and chronic abscesses respectively were bacteria-free (Table 1 ).

Identified germs are facultative and obligate anaerobes (Table 1). Among the facultative anaerobe bacteria, the Gram+ cocci accounted for the highest percentage. The Chi-Square Goodness of Fit test showed statistical significance for the gram+ cocci in the facultative anaerobes group $(p=0.001)$. This test could not be applied to the obligate anaerobes (only one type of germs: GPB). Germs that do not belong to the commensal oral microflora were identified: 1 staphylococcus aureus, 2 clostridium perfringens, 1 proteus mirabilis and 1 listeria grayi (Table 1 ).

The bacteria identified in samples obtained from canals of teeth with acute abscesses treated with anitbiotics are described in table 2. 


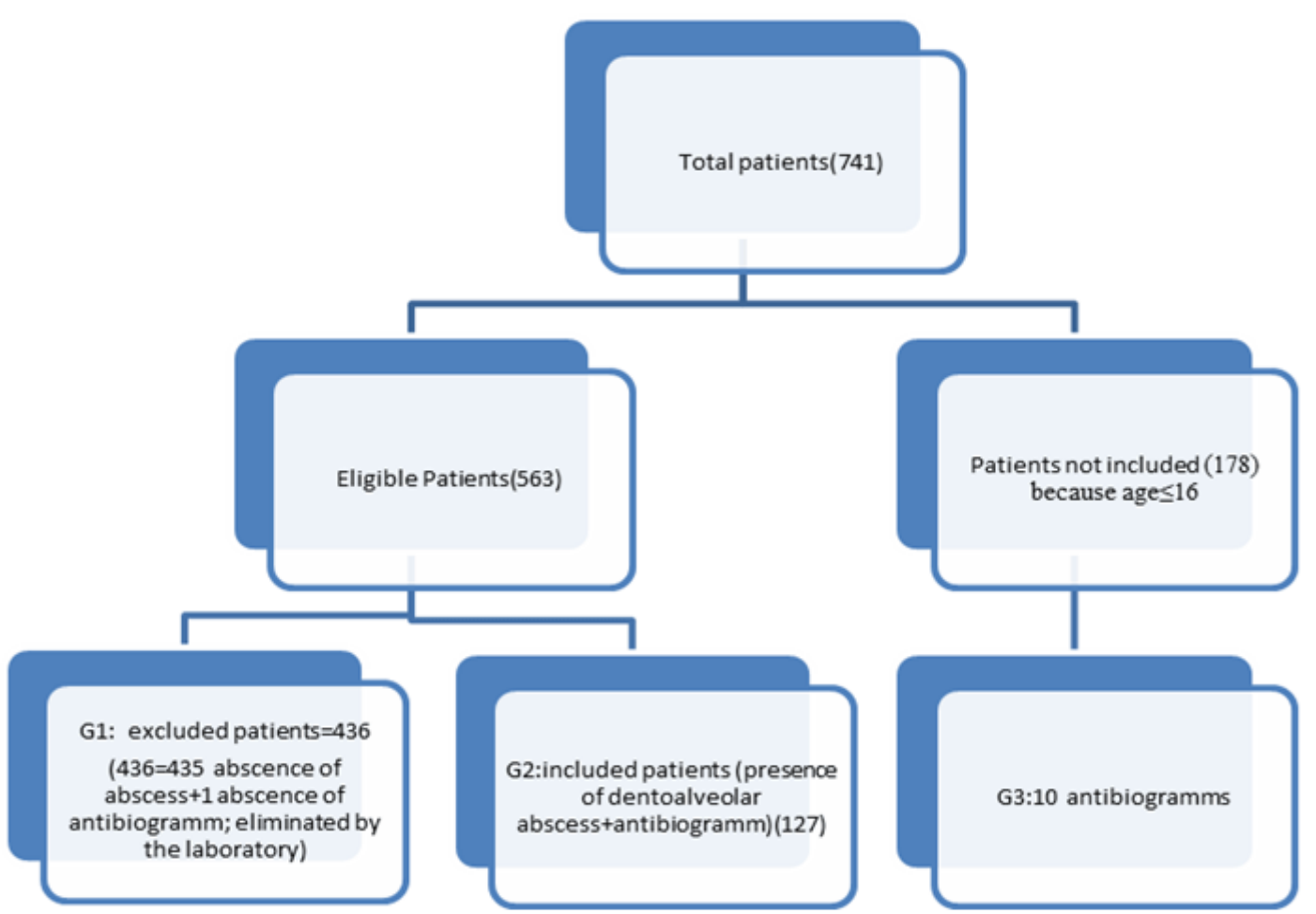

Flowchart: Scheme of the study model. G1: group of patients excluded because absence of dento-alveolar abscess or antibiogramm; G2: group of patients included with dentoalveolar abscess + antibiogramm; G3: group of patients with antibiogramm not included because their age $\leq 16$

Table 1: Description of Laboratory Results

\begin{tabular}{|c|c|c|c|c|c|}
\hline Results Lab & Type & Germs identified & Acute abscess & Chronic abscess & Total Germs N (\%) \\
\hline Anaerobes & GNB & Proteus Mirabillis & $1(1.03 \%)$ & & $1(0.67 \%)$ \\
\hline Facultative & Total GNB & & 1 & & $1(0.67 \%)$ \\
\hline \multirow[t]{14}{*}{ Germs N= 135} & GPB & ARTHROBACTER SPECIES & $1(1.03 \%)$ & & $1(0.67 \%)$ \\
\hline & & LISTERIA GRAYI & & $1(1.92 \%)$ & $1(0.67 \%)$ \\
\hline & Total GPB & & 1 & 1 & $2(1.34 \%)$ \\
\hline & GPC & ABIOTROPHIA ADIACENS & $0(0.0 \%))$ & $1(1.92 \%)$ & $1(0.67 \%)$ \\
\hline & & AEROCOCCUS VIRIDANS & $9(9.27 \%)$ & $2(3.84 \%)$ & $11(7.38 \%)$ \\
\hline & & $\begin{array}{c}\text { ENTEROCOCCUS } \\
\text { FAECALIS }\end{array}$ & $6(6.18 \%)$ & $2(3.84 \%)$ & $8(5.36 \%)$ \\
\hline & & GEMELLA HAEMOLYSANS & $6(6.18 \%)$ & $3(5.76 \%)$ & $9(6.04 \%)$ \\
\hline & & $\begin{array}{c}\text { GEMELLA } \\
\text { MORBILLORUM }\end{array}$ & $6(6.18 \%)$ & $1(1.92 \%)$ & $7(4.69 \%)$ \\
\hline & & LACTOCOCCUSCREMORIS & $4(4.12 \%)$ & $1(1.92 \%)$ & $5(3.35 \%)$ \\
\hline & & LEUCONOSTOC SPECIES & $6(6.18 \%)$ & $4(7.69 \%)$ & $10(6.71 \%)$ \\
\hline & & $\begin{array}{l}\text { STAPYLOCOCCUS } \\
\text { EPIDERMIDIS }\end{array}$ & $6(6.18 \%)$ & $4(7.69 \%)$ & $10(6.71 \%)$ \\
\hline & & $\begin{array}{c}\text { STAPHYLOCOCCUS } \\
\text { AUREUS }\end{array}$ & $1(1.03 \%)$ & $0(0.0 \%)$ & $1(0.67 \%)$ \\
\hline & & STREPTOCOCCUS & $43(44.32 \%)$ & $27(51.92 \%)$ & $70(46.97 \%)$ \\
\hline & Total GPC & & 87 & 45 & 132(88.59\%) \\
\hline
\end{tabular}

Citation: Ghada A, Dominique C, Mokhbat J, Lemdani M, Ahmed H and Ayoub F. Evaluation of Sensitivity and Resistance 


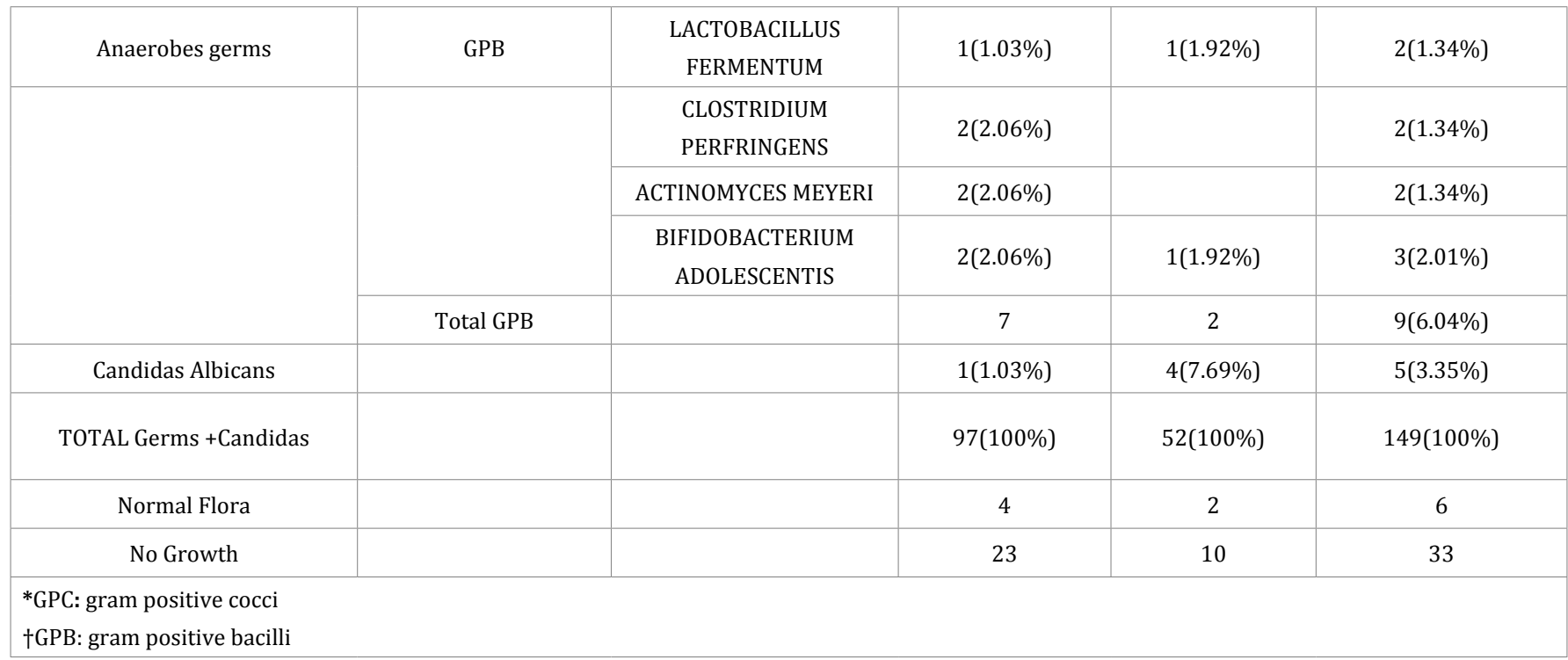

Table 2: Results for acute abscess with aggravating clinical signs

\begin{tabular}{|c|c|c|}
\hline \multicolumn{2}{|c|}{ Germs (N \%) } & \multirow{2}{*}{$\begin{array}{c}\text { Germs identified } \\
\text { AEROCOCCUS VIRIDANS }\end{array}$} \\
\hline Anaerobes facultative $(73.1 \%)$ & GPC* $18(94.73 \%)$ & \\
\hline & & ENTEROCOCCUS FAECALIS \\
\hline & & GEMELLA HAEMOLYSANS \\
\hline & & LACTOCOCCUSCREMORIS \\
\hline & & LEUCONOSTOC SPECIES \\
\hline & & STREPTOCOCCUS \\
\hline Anaerobe $1(3.8 \%)$ & $\mathrm{GPB}+1(5.27 \%)$ & ACTINOMYCES MEYERI \\
\hline No germs $6(23.1 \%)$ & & NO GROWTH \\
\hline Fungus $1(3.8 \%)$ & & CANDIDAS ALBICANS \\
\hline \multicolumn{3}{|l|}{ *GPC: gram positive cocci } \\
\hline GPB: gram positive bacilli & & \\
\hline
\end{tabular}

Germs sensitivity is presented in table 3. Moreover, the proportion of the resisting germs during a prescription for the case of an acute abscess or chronic abscess was $28.87 \%$ and $20.43 \%$ for erythromycin and clindamycin respectively; whereas it was $9.85 \%$ for penicillin.

Charts (Figures 1, 2 and 3) list bacterial resistance to penicillin, erythromycin and clindamycin.

\section{Discussion}

The microorganisms of the buccal cavity microbial flora are complex and multivariate. The normal oral flora is colonized at $95 \%$ by the facultative and aerobe streptococcus [9]. In the case of primary infection, the most frequently identified germs in the case of acute or chronic abscesses are Gram-positive and -negative bacteria with the predominance of the latter [10].

The results of our study stemming from the 88 specimens revealed the isolation of 144 germs and 5 fungi. So, in average,
1.69 germs/specimen were isolated. Our results are almost identical to those of Lysakowska et al. (1.5 germs/specimen) in the case of primary infections [10].

Several studies revealed that the cultivated germs of dental canals were facultative and obligate anaerobes [11, 12]. A significant prevalence of obligate anaerobes was reported by Gomes et al. [13], Foschi et al. [12]. The present study, similar to Shucaite et al. [14] and Lyzaskowska et al. [10] confirmed the predominance of facultative anaerobes ( $\mathrm{n}=135)$; only 9 obligate anaerobes were found (significance value). This can be explained by the difficulty to cultivate obligate anaerobe germs via standard culture methods or the exposure of germs to oxygen at the time of sampling.

Several studies described an important diversity of the canal microbiome in the case of primary infections $[11,15]$. In the present study, this diversification of germs in primary infection of the canal microbiome was identified in both types of acute 
Table 3: Results of susceptibility test to the following antibiotics

\begin{tabular}{|c|c|c|c|c|c|c|}
\hline \multicolumn{2}{|c|}{ ANTIBIOTICS } & \multirow{2}{*}{$\begin{array}{l}\text { GNBT } \\
\mathrm{N}(\%)\end{array}$} & \multirow{2}{*}{$\begin{array}{l}\text { GPB } † \\
\mathrm{~N}(\%)\end{array}$} & \multirow{2}{*}{$\begin{array}{l}\text { GPC* } \\
\mathrm{N}(\%)\end{array}$} & \multirow{2}{*}{$\begin{array}{c}\begin{array}{c}\text { Total germs identified } \\
\text { with antibiotics }\end{array} \\
\text { susceptibility (cases=127) } \\
N(\%)\end{array}$} & \multirow{2}{*}{$\begin{array}{c}\begin{array}{c}\text { Total Germs with antibiotics } \\
\text { susceptibility in aggravating cases } \\
\text { (cases=19) }\end{array} \\
\mathrm{N}(\%)\end{array}$} \\
\hline & & & & & & \\
\hline \multirow{3}{*}{ Penicillin } & Resistant & $0(0 \%)$ & $0(0 \%)$ & $14(10.68 \%)$ & $14(9.86)$ & $2(10.53)$ \\
\hline & Sensitive & $0(0 \%)$ & $11(100 \%)$ & $117(89.32 \%)$ & $128(90.14 \%)$ & $17(89.47)$ \\
\hline & Total & $0(0 \%)$ & $11(100 \%)$ & $131(100 \%)$ & $142(100 \%)$ & $19(100 \%)$ \\
\hline \multirow{3}{*}{ Cephalotin } & Resistant & $0(0 \%)$ & $1(50 \%)$ & $8(7.0 \%)$ & $9(7.63 \%)$ & $2(11.76 \%)$ \\
\hline & Sensitive & $1(100 \%)$ & $1(50 \%)$ & $107(93.0 \%)$ & $109(92.37 \%)$ & $15(88.24 \%)$ \\
\hline & Total & $1(100 \%)$ & $2(100 \%)$ & $115(100 \%)$ & 118(100\%) & $17(100.0 \%)$ \\
\hline \multirow{3}{*}{ Tetracycline } & Resistant & $1(100 \%)$ & $0(0 \%)$ & $20(15.38 \%)$ & 21(15.79) & $6(33.33 \%)$ \\
\hline & Sensitive & $0(0 \%)$ & $2(100 \%)$ & $110(84.62 \%)$ & $112(84.21 \%)$ & $12(66.67 \%)$ \\
\hline & Total & $1(100 \%)$ & $2(100 \%)$ & $130(100 \%)$ & $133(100 \%)$ & $18(100.0 \%)$ \\
\hline \multirow{3}{*}{ Erythromycin } & Resistant & $0(0 \%)$ & $0(0 . \%)$ & $41(31.30 \%)$ & $41(28.87 \%)$ & $6(31.57 \%)$ \\
\hline & Sensitive & $0(0 \%)$ & $11(100 \%)$ & $90(68.70 \%)$ & 101(71.13\%) & $13(68.43 \%)$ \\
\hline & Total & $0(0 \%)$ & $11(100 \%)$ & $131(100 \%)$ & $142(100 \%)$ & $19(100 \%)$ \\
\hline \multirow{3}{*}{ Clindamycin } & Resistant & $0(0 \%)$ & $0(0 \%)$ & $28(22.22 \%)$ & $28(20.44 \%)$ & $4(22.23 \%)$ \\
\hline & Sensitive & $0(0 \%)$ & $11(100 \%)$ & $98(77,78 \%)$ & $109(79.64 \%)$ & 14(77.77\%) \\
\hline & Total & $0(0 \%)$ & $11(100 \%)$ & $126(100 \%)$ & $137(100 \%)$ & $18(100 \%)$ \\
\hline $\begin{array}{l}\text { *GPC: gram pos } \\
\text { †GPB: gram po } \\
\text { ҒGNB: gram n }\end{array}$ & $\begin{array}{l}\text { e cocci } \\
\text { ge bacilli } \\
\text { ative bacilli }\end{array}$ & & & & & \\
\hline
\end{tabular}

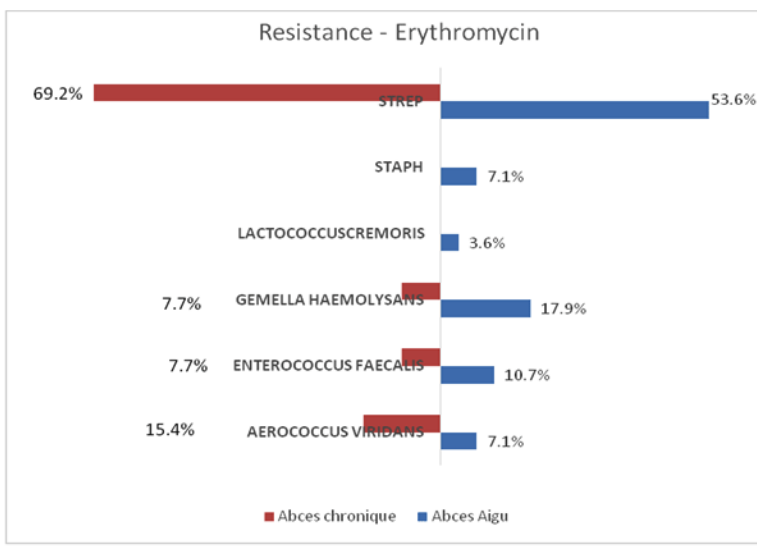

Figure 1: Resistance to erythromycin in acute and chronic abscess

and chronic abscesses (Table 1). Moreover, primary infections are generally due to Gram-negative anareobe germs [16]. In this study, in both types of abscesses, almost the totality of germs were Gram positive $(134 / 149=95.97 \%)$ except for one $(0.67 \%)$ (proteus mirabilis) which did not belong to the canal microbiome (Table 1). Likewise, the majority of germs were cocci $(n=132$, 91.67\%). Twelve bacilli-type bacteria were detected out of which 9 represent the totality of anaerobe (Table 1). The Chi-Square

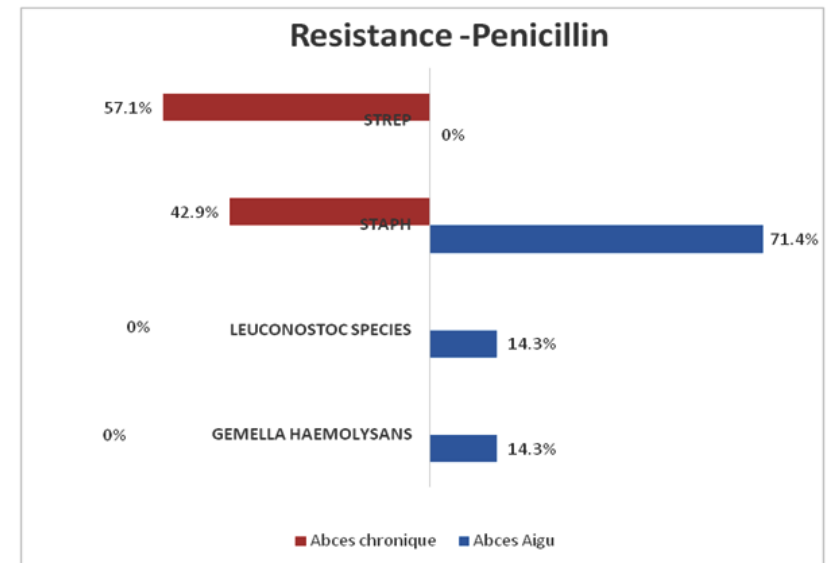

Figure 2: Resistance to penicillin in acute and chronic abscess

Goodness of Fit test was significant for the facultative anaerobe germs $(p=0.001)$. Streptococci are the most prevailing germs of canal infections [11]. Our microbiological results confirmed their prevalence, the streptococcus family (streptococcus viridans, leuconostoc spp 10/144, gemella morbillorum 7/144 and heamolysans 9 /144, aerococcus viridans 11/144, lactococcus cremoris 5/144 and abiotrophia adiacens 1/144) account to the highest percentage $113 / 149$ (75.83\%) followed by the 
Resistance- Clindamycin

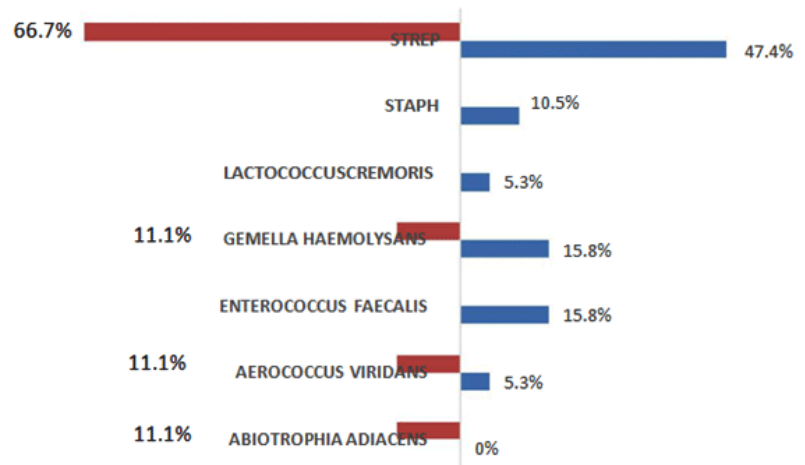

Figure 3: Resistance to clindamycin in acute and chronic abscess

staphylococcus $(11 / 149=7.38 \%)$ out of which 10 are epidermidis $(6.75 \%)$ and 1 staphylococcus aureus $(0.67 \%)$ are majority in these infections; they are followed by the enterococci $(8 / 149=5.36 \%)$ (Table 4). Enterococci are prevailed in other studies in the case of primary and secondary infections [9]; while the percentage of staphylococci fell within the interval of other studies [17].

Concerning anaerobe germs, some Bifidobacterium (Bacteroids), Lactobacillus, Actinomyces meyeri and Clostridium perfringens were detected confirming the results of previous studies $[18,19]$.

Moreover, candidas albicans, eukariotes, are germs that can colonize the oral flora. They are detected in primary infections and identified at $21 \%$ by molecular methods $[18,20]$. Our results showed a rate of $3,35 \%$ with $4 / 5$ candidas identified in a chronic abscess for smoking patients. Many identified bacteria did not belong to the commensal flora: Proteus mirabellis, Listeria grayi, and staphylococci aureus (Table 1). These germs were detected at previously hospitalized elderly patients.

The development of a purulent infection necessitates a synergetic interdependence among aerobe and anaerobe germs [21]. At the beginning of the infection, the aerobe germs consume the oxygen of the pulp chamber turning the milieu into poor in oxygen [3]. Hence, the germs living in anaerobiosis will develop in an environment rich in nutrients and poor in oxygen or lacking oxygen, which results into a shift of the facultative aerobe pathogen flora into an anaerobe flora.

On the other hand, it is important to know that cellulitis is caused by streptococcus. Streptococcus destroys the fibrin and the conjunctive tissue with their enzymes (streptokynase...) facilitating thus the diffusion of the infection through the facial plans [22]. Moreover, the anatomy of the facial plans of the orofacial sphere and the neck act as an inefficient barrier rendering the diffusion of the infection between the facial plans a prominent risk. Thus, in addition to the clinical diagnosis, it is important to identify the causal tooth and the localization of these apices relative to the facial plan. An increased incidence of diffuse dental infections was reported [9]; the high level of isolated streptococcus confirms the importance of immediate care of these dental infections. Streptococci milleri are associated with other germs such as Porphyromonas and Prevotella in the formation of acute dental abscesses. Those bacteria were not detected in the present study, which can be explained by the chosen microbiological method that is inappropriate for their identification. Moreover, staphylococcus was isolated in $11.1 \%$ of the specimens. Also, the complication of their infections can lead to sepsis emphasizing the critical importance of an early and appropriate management of dental infections.

Facultative anaerobe germs Gram (+) cocci prevailed in all the acute abscesses; obligate anaerobe germs were detected only in the group with aggravating clinical signs. The predominance of Gram (+) cocci in moderate dental infections has been shown with a shift of the flora in obligate anaerobia with time [3]. In fact, in this study, all cases can be considered with moderate infection rather than severe and not requiring hospitalization. Moreover, a Candidas albicans was identified. The presence of Candidas albicans in the pus culture is supported by the literature [3].

Sensitivity tests results showed that penicillin has almost the same sensitivity level, while clindamycin followed by erythromycin score less important levels (Table 3). Result analysis showed that Gram (+) cocci are the germs that showed the most resistance especially to erythromycin and Clindamycin (Table 3). The proportion of the resistance germs was more important in the group of erythromycin (28.87\%) and clindamycin $(20.43 \%)$ and less important in the group of penicillin (9.85\%). Therefore, antibiotherapy at narrow spectrum, such as penicillin can be favored at first. An antibiotherapy is chosen according to several criteria: i) the causative pathogen agent ii) the susceptibility to the chosen molecule and iii) the absence of antibiotic resistance of the pathogen. Therefore, several studies $[2,23]$ and international guidelines (AHA, BSC), recommended the B-lactam family and more specifically the penicillin at first for its narrow spectrum, its lesser interference with the bacterial flora and a lesser risk of development of super infection [2]. According to the present results involving the Lebanese population, penicillin should be the first choice antibiotics for the treatment of dental infections when appropriate due to its level of resistance (acceptable $<10$ ) and its narrow spectrum.

The sensitivity of germs isolated from teeth with acute abscesses with and without an aggravating sign, was similar in percentage for the various antibiotics but with a small reduction of the percentage for the latter. Penicillin remained the best choice.

The resistance of germs to penicillin, erythromycin, and clindamcyn is reported in figure 1, 2 and 3. The isolated resisting germs represented in these figures are Gram (+) cocci. Streptococcus viridans prevailed, followed by staph for penicillin for both cases of dental abscesses. This can be explained by the development of important resisting germs among Streptococcus viridans [2]. Gemellas and Enterococci other than streptococcus revealed a resistance to erythromycin and Clindamycin especially in the form of chronic abscesses. Gemellas are among the 
germs resisting to penicillin. Hence, Gemellas and Enterococci showed resistance to erythromycin and clindamycin, other than streptococcus. It is noteworthy that staphylococci and enterococci are among the most dangerous resisting germs about which several studies $[2,24]$ called for attention while prescribing antibiotics to reduce the risk of their development

\section{Conclusions}

Within the limitations of this study the following conclusions can be drawn:

- The canal flora of teeth associated with acute or chronic abscesses was diversified; facultative and obligate anaerobic germs were present in both types of abscesses.

- Dangerous germs (Staphylococus aureus, Proteus mirabillis, Listeria grayi) were identified, highlighting the importance of the dentists' role with their prescriptions and in the development rate of resisting germs.

- Penicillin, a narrow-spectrum antibiotic with resistance levels $<10 \%$, should be the first choice for Lebanese dentists for the management of primary infections.

- Development of important resistant germs among streptococcus viridans.

- Enterococci and Gemellas are gaining resistance. Dentist should be pertinent with their choice of antibiotics to reduce the risk of development of resistant germs especially for enterococci.

\section{References}

1. Craig Baumgartner J, Tian Xia. Antibiotic Susceptibility of Bacteria associated with Endodontic Abscesses. J Endod. 2003;29(1):44-47.

2. Handal T, Olsen I. Antimicrobial resistance with focus on oral betalactamases. Eur J Oral Sci. 2000;108(31):163-174.

3. Siqueira José F Jr. Treatment of Endodontic Infections. Quintessence Publishing. 2011.

4. Poveda-Roda R, Bagán JV, Sanchis-Bielsa JM, Carbonell-Pastor E. Antibiotic use in dental practice. A review. Med Oral Patol Oral Cir Bucal. 2007;12(3):186-192.

5. Hunter A, Kalathingal S, Shrout M, Plummer K, Looney S. The effectiveness of a pre-procedural mouth rinse in reducing bacteria on radiographic phosphor plates. Imaging Sci Dent. 2014;44(2):149-154. doi: 10.5624/isd.2014.44.2.149

6. Neves MA, Rôças IN, Siqueira JF Jr. Clinical antibacterial effectiveness of the self-adjusting file system. Int Endod J. 2014;47(4):356-365. doi: 10.1111/iej.12151

7. Sögren U, Figdor, Persson S, Sundqvist G. Influence of infection at the time of root filling on the outcome of endodontic treatment of teeth with apical periodontitis. Int Endod J. 1997;30(5):297-306. DOI: 10.1046/j.1365-2591.1997.00092.x

8. American Assiociation of Endodontists Endodontic. ENDODONTICS: Colleagues for Excellence. Diagnosis. Fall. 2013.

9. Sandor GK, Low DE, Judd PL, Davidson RJ. Antimicrobial Treatment Options in the Management of Odontogenic Infections. J Can Dent Assoc. 1998;46(2):508-514.
10.Łysakowska ME, Ciebiada-Adamiec A, Sienkiewicz M, Sokołowski J \& Banaszek K. The cultivable microbiota of primary and secondary infected root canals, their susceptibility to antibiotics and association with the signs and symptoms of infection. Int Endod J. 2016;49(5):422430. doi: 10.1111/iej.12469

11. Siqueira JF Jr, Rôças IN. Polymerase chain reaction based analysis of microorganisms associated with failed endodontic treatment. Oral Surg Oral Med Oral Pathol Oral Radiol Endod. 2004;97(1):85-94.

12. Foschi F, Cavrini F, Montebugnoli L, Stashenko P, Sambri V, Prati C. Detection of bacteria in endodontic samples by polymerase chain reaction assays and association with defined clinical signs in Italian patients. Oral Microbiol Immunol. 2005;20(5):289-295.

13. Gomes BP, Pinheiro ET, Gade-Neto CR, Sousa EL, Ferraz CC, Zaia AA et al. Microbiological examination of infected dental root canals. Oral Microbiol Immunol. 2004;19(2):71-76.

14. Skucaite N, Peciuliene V, Vitkauskiene A, Machiulskiene V. Susceptibility of endodontic pathogens to antibiotics in patients with symptomatic apical periodontitis. J Endod. 2010;36(10):1611-1616. doi: 10.1016/j.joen.2010.04.009

15. Sakamoto M, Jr Siqueira JF, Rocas IN, Benno Y. Molecular analysis of the root canal microbiota associated with endodontic treatment failures. Oral Microbiol Immunol. 2008;23(4):275-281. doi: 10.1111/j.1399302X.2007.00423.x

16. Fouad AF, Zerella J, Barry J, Spangberg LS. Molecular detection of Enterococcus species in root canals of therapy resistant endodontic infections. Oral Surg Oral Med Oral Pathol Oral Radiol Endod. 2005;99(1):112-118.

17. Shweta and Krishna Prakash S. Dental abscess: A microbiological review. Dent Res J. 2013;10(5):585-591.

18. Molander A, Reit C, Dahle'n G, Kvist T. Microbiological status of root filled teeth with apical periodontitis. Int Endod J.1998;31(1):1-7. DOI: 10.1046/j.1365-2591.1998.t01-1-00111.x

19. Chävez De Paz LE, Daylen G, Molander A, Möller A, Bergenholtz G. Bacteria recovered from teeth with apical periodontitis after antimicrobial endodontic treatment. Int Endod J. 2003;36(7):500508.

20. Baumgartner JC, Watts CM, Xia T. Occurrence of candidas albicans in infections of endodontic origin. J Endod. 2000;26(12):695-698.

21. Barclay JK. Antibiotics revisited. N Z Dent J. 1990;86(384):44-47.

22. Grodinsky M, Holyoke EA. The Fasciae and facial spaces of the head, neck and adjacent regions. Am J Anat, 1938;63(3):367-408. DOI: 10.1002/aja.1000630303

23. Al-Haroni Mohammed and Skaug Nils. Incidence of antibiotic prescribing in dental practice in Norway and its contribution to national consumption. J Antimicrob Chemother. 2007;59(6):11611166.

24. Lewis MAO. Why we must reduce dental prescription of antibiotics: European union antibiotic awareness day. Br Dent J.2008;205(10):537538. doi: $10.1038 /$ sj.bdj.2008.984 